\title{
Mentor, Educator, Friend: a Tribute to Robert M. Chamberlain, PhD
}

\author{
Carrie Cameron • Amr Soliman • Shine Chang
}

Published online: 28 January 2012

(C) Springer Science+Business Media, LLC 2012

The participants of the "Future Directions in Cancer Prevention \& Control: Workforce Implications for Training, Practice, \& Policy" symposium paid tribute at a special event to one of the major shapers of the cancer prevention and control workforce of the last 25 years, Dr. Robert M. Chamberlain. Dr. Chamberlain's contributions to training and mentoring junior scientists in the field have resulted in the creation of generations of productive, well-prepared cancer prevention and control researchers and practitioners.

Dr. Chamberlain, a University of Texas Distinguished Teaching Professor, recently retired in 2009 as Professor of Epidemiology at the University of Texas MD Anderson Cancer Center. In 1992 he founded the National Cancer Institute-funded Cancer Prevention Research Training Program, one of the oldest, largest, and most comprehensive training programs dedicated to cancer prevention research in the country. The multidisciplinary training program prepares graduate students and pre-doctoral and

C. Cameron $(\bowtie) \cdot$ S. Chang

Cancer Prevention Research Training Program,

UT MD Anderson Cancer Center,

1155 Pressler-Unit 1365 ,

Houston, TX 77007, USA

e-mail: ccameron@mdanderson.org

S. Chang

e-mail: shinechang@mdanderson.org

\section{A. Soliman}

Medical School, 5626 SPH,

1415 Washington Heights,

Ann Arbor, MI 48109-2029, USA

e-mail: asoliman@umich.edu postdoctoral fellows to pursue careers as laboratory, behavioral, population science, and clinical researchers. With his retirement, Dr. Chamberlain's legacy has been continued by Dr. Shine Chang, who now serves as director of the training program and PI on the grant awards that support the program.

Dr. Chamberlain graduated from Westminster College in Missouri in 1964 with a degree in Sociology and Anthropology. While at Westminster, he was a member of Phi Gamma Delta fraternity. After obtaining his Bachelor's degree, Chamberlain continued his studies in Sociology and Anthropology at the University of Missouri-Columbia, earning a Master's degree in 1967 with an emphasis in social gerontology and his $\mathrm{PhD}$ degree in medical sociology and anthropology in 1969. He completed postdoctoral training in computing applications for the social and behavioral sciences at the University of Colorado, Boulder.

After serving as a captain in the Office of the Army Surgeon General and member of the graduate faculty at Brooke Army Medical Center in San Antonio (19691971), Dr. Chamberlain was named assistant professor of sociology and a research associate in program effectiveness studies at the University of Virginia from 1971 to 1975 . He then joined Baylor College of Medicine in Houston as an assistant professor of community medicine. Dr. Chamberlain went on to serve as an assistant professor in the Graduate School of Social Work at The University of Houston (1976-1979) and coordinator of the Cancer Prevention Training Program and research assistant professor in the Education Division of the Debakey Heart Center at Baylor College of Medicine (1979-1988). 
Dr. Chamberlain joined the faculty of the University of Texas MD Anderson Cancer Center in 1988, when he was named assistant professor of cancer prevention, associate epidemiologist, and associate health educator in the then Department of Cancer Prevention (which has since grown into a division housing four departments) with Dr. Margaret R. Spitz and under the leadership of Dr. Guy Newell. In 1992, he transitioned to the new Department of Epidemiology with Dr. Spitz as chair and was promoted to associate professor and deputy department chair in 1994. In 1999, Dr. Chamberlain was promoted to full professor and named Ashbel Smith Professor, continuing his research focus on epidemiologic studies of the social risk factors for cancer and developing new methods of recruitment and adherence in cancer prevention clinical trials. Following the retirement of his long-time colleague and chair of Epidemiology, he served as interim chair for the department during an international search for the new chair. Dr. Chamberlain has also served the faculty of the University of Texas Graduate School of Biomedical Sciences and as adjunct faculty for the University of Texas School of Public Health.

Dr. Chamberlain is widely recognized for his deep commitment to mentoring and educating junior scientists. In 1995, he received the highly prestigious MD Anderson Julie \& Ben Rogers Award for Excellence in Cancer Prevention; in 1999, he received the MD Anderson Faculty Achievement Award in Education; in 2005, the annual Robert M. Chamberlain Distinguished Mentor Award was created in his honor, to recognize excellence in mentoring by the MD Anderson Postdoctoral Association. In 2007, he was named Distinguished Teaching Professor in The University of Texas System and, since 2005, has been a charter member of the University of Texas Academy of Health Science Education and its sister chapter at MD Anderson. For his service to the University of Texas Graduate School of Biomedical Science, he has received the Dean's Excellence Award six times since 1995. He received in 2005 the Margaret Hay Edwards Medal, the highest honor for outstanding contributions in cancer education awarded by the American Association for Cancer Education and, in 2007, the Alumni Achievement Award from his alma mater, Westminster College. He has served a number of NIH review committees over time, including as a permanent member and then chair of Subcommittee G-Education of the NCI Scientific Review Group. He has directly supervised 65 graduate students and 23 postdoctoral fellows, served on supervisory committees for 12 trainees, and mentored many more. He serves as co-investigator on another MD Anderson training program, the K12 Clinical Oncology Research Career Development
Program, and is an advisor and former director of the Community Outreach and Education program of the NIEHS Center for the Study of Environmental Disease. Dr. Chamberlain has developed educationally based recruitment strategies for chemoprevention trials and was a member of the Outcomes Committee of the Radiation Therapy Oncology Group. In addition, Dr. Chamberlain consults extensively with other training programs across the country and with those wishing to establish training programs.

Since 1996, Dr. Chamberlain has been the principal investigator, a co-investigator, or a co-director for eight funded research projects and a grant reviewer for several study sections. He is an associate editor for the Journal of Cancer Education and a reviewer for Cancer Epidemiology Biomarkers \& Prevention. His publications number more than 65 articles published in peer-reviewed journals, seven manuals, two invited articles, two book chapters, and a book over his career. His professional memberships include the American Sociological Association; American Public Health Association; American Association for Cancer Education, of which he is a past president; the American Society for Preventive Oncology; Society for Clinical Trials; Society for Behavioral Medicine; and the European Association for Cancer Education.

Dr. Chamberlain's extensive international collaborations began with his first visit to Egypt in 1996. He has visited Egypt 18 times over the years and has established strong educational and research collaborations with many Egyptian cancer educators, cancer centers, and universities. He was awarded the medal of Cairo University in 2010 for his achievements and outstanding contributions in strengthening the academic relationship between Egypt and the USA. Dr. Chamberlain has been an active member of the Middle East Cancer Consortium (MECC) since 1998. MECC is funded by NCI to promote cancer research and educational activities of its member countries (Egypt, Cyprus, Israel, Jordan, Palestine, and Turkey). Dr. Chamberlain has coordinated several conferences and special workshops of MECC that have advanced the joint collaborations of its member countries. As Professor of Epidemiology at the University of Michigan School of Public Health and member of the University Comprehensive Cancer Center, he co-leads the Cancer Epidemiology Education in Special Populations Program. Through this program, he mentors students who conduct research in Africa and the Middle East. He has strong connections with oncologists and cancer researchers who mentor students in Egypt, Morocco, Tunisia, Ghana, Tanzania, Uganda, Lebanon, Saudi Arabia, and Turkey. Dr. Chamberlain is a regular lecturer at the University of Michigan Graduate Summer Session in Epidemiology, 
an international course taught every summer in a different country in Africa and the Middle East. He also provides invaluable advice to African and Middle Eastern early career researchers on career development and possible collaborations with US academic institutions.

Dr. Chamberlain and his wife Pam reside in Wimberley, Texas, and have three daughters and four grandchildren. Although he continues to maintain part-time faculty appointments at MD Anderson and the University of Michigan School of Public Health, he and Pam enjoy their semiretirement traveling, visiting with family and friends, and collecting, restoring, and rallying antique sports cars, particularly Morgans and Austin Healeys.
As one of the most influential and productive rainmakers in the field of cancer prevention over more than two decades, Dr. Chamberlain's contributions cannot be numbered. We dedicate the symposium and this supplement to him.

Acknowledgement The authors wish to acknowledge Ms. Kava Lewis of MD Anderson Cancer Center for her valuable contributions to this tribute.

Conflict of Interest The authors declare that they have no conflict of interest. 